\title{
Estratificación violenta en los personajes de La ciudad y los perros
}

\author{
Violent Stratification in the Characters of The Time of the Hero
}

\author{
Jesús Miguel Delgado Del Aguila \\ Escuela de Literatura, Facultad de Letras y Ciencias Humanas, Universidad Nacional Mayor de San Marcos, Lima, Perú \\ *Autor a quien se dirige la correspondencia: tarmangani2088@outlook.com
}

Recibido: 12 de febrero de 2021 / Aceptado: 02 de septiembre de 2021

\section{Resumen}

$\mathrm{E}$ ste artículo examina La ciudad y los perros (1963) de Mario Vargas Llosa para fundamentar cómo se logra la estratificación teórica de estilos y técnicas que se emplean para abordar la violencia en el texto. Sobre la epistemología, recurre principalmente a Todorov, Hamburger, Lotman y Genette. Y, para argumentar la manifestación de la violencia, considera las eventualidades que padecen los personajes del Colegio Militar Leoncio Prado; en especial, el Jaguar, el Poeta y el Esclavo. Esas acciones serán justificadas por la instrucción castrense, la evolución humana, la necesidad de una conducta hegemónica idónea y la búsqueda del efecto perlocutivo en el lector. Para sistematizar esas peculiaridades, se opta por una metodología adscrita al cotejo de información teórica para que sea confrontada con el discurso literario. El análisis que se desarrolla es complementado con fragmentos representativos para que las formulaciones sean más directas y convincentes. Como resultado, se confirma esa correspondencia entre las teorías heterogéneas, la novela y la interpretación, por lo que el concepto de violencia adoptaría una multidimensionalidad que evidencia su existencia y su requerimiento esencial en los personajes. Con ello, se sustenta como conclusión que la violencia en ese contexto debería ser permanente e imprescindible para subsistir.

Palabras clave: oom latinoamericano, novela de la violencia, técnicas literarias, narrativa del siglo XX, literatura peruana

\section{Abstract}

$\mathrm{T}$ his paper examines La ciudad y los perros (1963) of Mario Vargas Llosa to establish how the theoretical stratification of styles and techniques used to address violence in the text is achieved. On epistemology, Todorov, Hamburger, Lotman and Genette, are mainly used. And, to argue the manifestation of violence, the eventualities suffered by the characters of the Leoncio Prado Military Academy, are considered; especially, the Jaguar, the Poet and the Slave. These actions will be justified by military instruction, human evolution, the need for an ideal hegemonic conduct and the search for perlocutionary effect on the reader. To systematize these peculiarities, a methodology ascribed to the collation of theoretical information is chosen so that it is confronted with the literary discourse. The analysis that is developed is complemented with representative fragments so that the formulations are more direct and convincing. As a result, this correspondence between the heterogeneous theories, the novel and the interpretation is confirmed, so that the concept of violence would adopt a multidimensionality that evidences its existence and its essential requirement in the characters. With this, it is sustained as a conclusion that violence in this context should be permanent and essential to survive.

Keywords: Latin American boom, novel of violence, literary techniques, 20th century narrative, Peruvian literature 


\section{Introducción}

La ciudad y los perros (1963) es una novela en la que se muestran tipos heterogéneos de violencia, que se articulan en la cotidianidad del Colegio Militar Leoncio Prado, con sus propias lógicas, organización y dinámica; en especial, en los cadetes que lo integran. En este estudio ${ }^{1}$, el propósito es argumentar que el estilo y las múltiples técnicas literarias utilizados por Mario Vargas Llosa se condicionan a las sensaciones de hegemonía y distinción que adoptan los personajes, una vez que asimilan el adiestramiento militar y pretenden sobrevivir en ese centro educativo. Desempeñarse con violencia es un hábito que actualiza su configuración respetable y ontológica de poder; aunque, para ello, actúan con agresividad y buscan la forma de destituir al resto. Asimismo, ese ritmo de vida impide que el trato que fluctúa en la institución no trastoque su dignidad. En la novela, la violencia es plasmada con constancia, lo cual generar un efecto atroz durante el proceso de lectura. Para ello, el autor recurre a una diversidad de mecanismos para que su diégesis sea perlocutiva.

Para empezar, se trabaja el estilo en el texto, tópico que ha sido abordado con anterioridad por Rama (2005/1984), Urroz (2011) y Valencia (1976). Por esa razón, retomo la conceptualización de Todorov que desarrolla en Literatura y significación (1971), en el que propone que este se diferencia por la expresión lingüística y la cosmovisión que se le atribuyen a una narración. Igualmente, se explican sus tres modalidades: el directo, el indirecto y el indirecto libre, según los postulados de Hamburger (1975), Todorov (1971) y Vargas Llosa y colaboradores. (1987). Estas se evidencian en el desenvolvimiento complejo del Jaguar en sus variados ámbitos sociales, así como al interactuar con los miembros del Círculo, el Flaco Higueras, Teresa y los cadetes del Colegio Militar Leoncio Prado. De esa manera, se corroborará con la hipótesis de esta evaluación: el requerimiento del protagonista de actuar de una determinada forma para adquirir poder y consideración de los demás. Asimismo, este tema estará orientado a precisar clasificaciones como las de estilos literarios teorizados por Todorov (1971) y niveles de lenguaje fundamentados por Lotman (1998)

1 El presente estudio se deriva de la investigación que culminó con la tesis "Protagonismo violento y modos de representación en $L a$ ciudad y los perros (1963)" defendida por su autor en la Universidad Mayor de San Marcos, Lima, Perú (Delgado Del Aguila, 2017). y analizados por Castro-Klarén (2006), Gnutzmann (1992) y Martín (1979), y que se estriban en justificar el empleo del habla agresiva e injuriante por el contexto represivo y castrense que se exige en la escuela.

Para terminar, se arguye el uso de las técnicas literarias en la diégesis. Para ello, reanudo el paradigma establecido por Genette $(1989,1998)$, quien advierte que esta es el relato del narrador y que está supeditada a lo estilístico. En este caso, esta modalidad es plural por la intención de Mario Vargas Llosa, quien procura demostrar la violencia consuetudinaria en el texto a través de prototipos hegemónicos que son transferidos a los protagonistas, como al presenciar que el Jaguar se distingue de los demás cadetes por sublevarse al no "bautizarse" como tradicionalmente lo hacen los alumnos de cuarto año con los ingresantes. Con el propósito de explicar esta tipología, recabo una taxonomía bajo la égida de la información y el tiempo. La primera consiste en la potestad del autor de distribuir lo necesario para que se desarrolle la novela y persuada con eficacia al lector, acotando que la agresividad será la constante en los involucrados y sus acciones, junto con la verosimilitud y el dramatismo originado. Un ejemplo preeminente se observa cuando se busca desentrañar al asesino del Esclavo o al dilucidar la identidad de los personajes a los que se han obviado sus nombres adrede y se han colocado en un mismo plan de expresión (mediante monólogos). Para que esa determinación fluctúe, se recurre a técnicas, tales como la trama, la paralipsis, la paralepsis, los vasos comunicantes, las cajas chinas, la confesión, la sorpresa y el suspenso. Estos términos fueron abordados por Bajtín (1998), Barthes (1977), Gálvez (1992), Gene tte (1989, 1998), Hawthorn (1997), Niñapayta citado por Tenorio (2001), Shaw (1999) y Todorov (1971). Además, han sido estudiados por la exégesis literaria, conformada por Baker (1977), Edwards (2011), Fontaine (2012), Harss (1966), León (2010), Moreno (1987) y Perera (1980). Y la segunda clasificación se vale del dominio del tiempo, que alega Ricoeur $(1995,1996,1998)$ como una instancia dinámica que se supedita al espacio y el estilo del autor con organización. El presente, el pasado y el futuro son propicios para comprender la función básica de este rubro. Sin embargo, se complementan otras variantes, tales como la intratemporalidad, la eternidad, la digresión, las velocidades y las frecuencias narrativas, desplegadas por Doležel (1999), Genette $(1989,1998)$, Ricoeur (1995, 1996, 1998) y Todorov (1971). Estas sirven para reincidir en la localización de los protagonistas (Ricardo 
Arana, Alberto Fernández y el Jaguar) y plasmarlos en la obra con el criterio autónomo del escritor peruano, así sea relatando sus historias o exhibiendo sus peculiaridades en torno a su desenvolvimiento. Las investigaciones que efectuó la crítica literaria encargada de confrontar esta temática fueron hechas por Castañeda (1987), de Felipe (2012), Díaz Reategui (2004), Kerr (1983) y Sommers (1976)

En ese sentido, este artículo demuestra que por medio del estilo y las técnicas literarias de Mario Vargas Llosa se refuerza la intención de querer representar la violencia en su máxima manifestación; a la vez, que se revela la composición de los personajes, quienes se respaldan de estrategias para sobrevivir en el Colegio Militar Leoncio Prado. Estas consisten en hacer uso recalcitrante de la agresividad y la fuerza.

\section{Los estilos en La ciudad y los perros (1963)}

Para Todorov (1971, pp. 13-16), el estilo ${ }^{2}$ se enfoca en el proceso autónomo de enunciación o representación de la realidad en el discurso, en el que se asimilan los registros verbales o lingüísticos y los puntos de vista; es decir, este se adscribe a la narración y los temas que se desarrollen. Para conseguirlo, el autor se vale de los recursos literarios y su experiencia. Desde lo narratológico, se conocen tres estilos, que se alternan en una diégesis: el directo, el indirecto y el indirecto libre. Primero, según Todorov (1971, p. 53), el estilo directo se evidencia mediante la reproducción sustancial de los diálogos de los personajes o las descripciones que realizan. Su objetivo es mantener informado al lector con respecto al progreso de la intriga. Verbigracia, en el siguiente fragmento, se mencionan a los participantes de la conversación: " - Cuatro - repitió el Jaguar- ¿QQuién? - Yo — murmuró Cava-. Dije cuatro. -Apúrate - replicó el Jaguar- Ya sabes, el segundo de la izquierda" (Vargas Llosa, 2012, p. 9). Segundo, para Todorov (1971, p. 106), el estilo

2 El estilo en La ciudad y los perros ha sido estudiado a partir de dos perspectivas medulares. La primera se enfoca en la revisión de la naturaleza transgresora, vanguardista y experimental que el autor ha dispuesto sobre la obra, y que es notoria a través de las técnicas literarias que emplea. En ese caso, los aportes de Rama (2005, p. 163) y Urroz (2011, p. 491) fueron de utilidad. Con respecto a la segunda perspectiva, esta se basa en el propósito de hallar un vínculo más cercano entre el lector con el texto; es decir, la condición sintagmática de la novela sería un pretexto para buscar una interacción poco tradicional pero más efectiva durante el proceso de lectura. Quien se ha referido a este postulado ha sido Valencia (1976). indirecto ${ }^{3}$ se refiere al proceso de enunciación del discurso, que es palmario cuando el narrador interfiere en lo dicho por los personajes con sus palabras; a la vez, predomina el tiempo remoto. En el siguiente caso, la diégesis simula una autoría del Jaguar desde la tercera persona, pero se nota con rapidez cómo el narrador interviene para desplazarlo a otro tiempo. Además, se incluye al relato otros personajes con la técnica literaria de las cajas chinas.

\footnotetext{
— Háblame un poco de la bendita tía — dijo el flaco Higueras-. ¿Fuiste a verla?

—Después — dijo el Jaguar-. Esa misma noche, cuando Teresa me contó lo de su tía, le pregunté si quería casarse conmigo.

-Sí - dijo Teresa-. Yo sí quiero. Pero ¿y mi tía?

-Que se vaya a la mierda - dijo el Jaguar (Vargas Llosa, 2012, pp. 466-467).
}

Tercero, para Hamburger (1995, pp. 65-66) y Vargas Llosa (1971, pp. 196-205), el estilo indirecto libre consiste en recurrir a la enunciación desde el pretérito, sin que esta tenga un valor significativo en el relato. Suele usarse oraciones largas y plasmarse tonos y voces que contribuyen a la identificación de los personajes. Debido a eso, es factible conocer sus perspectivas. A ello, se plantea a un narrador omnisciente e impersonal en 3. ${ }^{\mathrm{a}}$ persona como una conciencia ambigua, que desorienta al lector al momento de querer detectar al interlocutor, puesto que podría tratarse de un personaje específico o el narrador principal. En la novela, existe esa confusión por el abordaje de los protagonistas (el Jaguar, el Poeta y el Esclavo) por la coincidencia de sus malas formaciones familiares. En la siguiente cita, es complejo hallar la asociación entre narrador personaje, ya que se oculta la identidad y el nombre del enunciador.

Ha olvidado también que al día siguiente estuvo mucho tiempo con los ojos cerrados después de despertar. Al abrirse la puerta sintió nuevamente que el terror se instalaba en su cuerpo. Contuvo la respiración. Estaba seguro: era él y venía a golpearlo. Pero era su madre [...]. Hasta que la madre dijo: "No podemos volver a Chiclayo nunca más. Tienes que vivir siempre con tu papá". Él se volvió a mirarla, convencido de que ella se derrumbaría de remordimiento, pero su madre estaba muy serena e, incluso, sonreía. "Prefiero vivir con la tía Adela que con él”, gritó [...]. Sin

3 El estilo indirecto en La ciudad y los perros ha sido abordado por Moreno (1987, p. 100), quien examina esta categoría para sustentar que esta podría ser considerada como técnica neorrealista. 
mirarlo a los ojos, le dijo: "Perdón por lo de anoche" (Vargas Llosa, 2012, pp. 135-136).

En síntesis, esta tipología de estilos empleada en la diégesis permitió la localización de la complexión intrínseca de los personajes, quienes desarrollan con frecuencia patrones violentos para estabilizarse y posicionarse en el ámbito castrense. Por otro lado, prevalece otra modalidad que facilita la estratificación del dialecto del autor en relación con los personajes. Me refiero a los estilos literarios y los niveles de lenguaje planteados por Lotman (1998) y Todorov (1971).

\section{Los estilos literarios: alto, medio y bajo}

Estos representan la identificación y el registro lingüístico del autor, con una determinada situación en el texto. Su nivel de la lengua se detecta en tres estilos literarios, que Todorov (1971, p. 233) ratifica: alto, medio y bajo. Estos conllevarán el entendimiento de cómo Vargas Llosa atribuye condiciones indispensables para que los personajes adquieran un valor hegemónico en función de los integrantes de ese centro educativo.

El primero se evidencia cuando la experiencia del autor es superior a la del lector. Si se alude a La ciudad y los perros, se manifiesta este caso con respecto a la organización social y militar en el texto, que indica una especialización y una documentación para abordar aspectos que no son del habla común, así como sus hábitos castrenses. Esto se demuestra en el siguiente fragmento, en el que el teniente Gamboa les recuerda al Jaguar y el Poeta que un cadete debe formarse cuando una autoridad está en frente de ellos: "Cuando entra un superior [...], los subordinados se cuadran. ¿Lo han olvidado? Tienen seis puntos cada uno. ¡Saque la mano de su cara y cuádrese, cadete!" (Vargas Llosa, 2012, p. 404). El estilo medio es cuando se presencia al lector común. Es palmario en las descripciones que hace el narrador en torno a la novela. Su comprensión no es rígida y se entiende, como en detallar un espacio indistinto con la mayor sencillez: "La formación se disuelve a medida que va ingresando al comedor; los cadetes se quitan las cristinas y avanzan hacia sus puestos hablando a gritos. Las mesas son para diez personas; los de quinto ocupan las cabeceras" (Vargas Llosa, 2012, p. 50). El estilo bajo se refiere al tono humorístico, que de alguna manera revela la insuficiencia del autor en función del lector. Este se plasma en los diálogos de los alumnos de esa escuela, quienes se diferencian por utilizar un dialecto coloquial, como se aprecia en la siguiente broma de doble sentido por parte de uno de los estudiantes: "Perra: minetera eres, y loca; ¿por qué no te mueres, cuando el Boa te la emboca entera?" (Vargas Llosa, 2012, p. 307).

A través de estos tres estilos literarios, se infiere que el alto se emplea cuando el narrador pretende configurar una atmósfera pertinente desde lo descriptivo. El medio y el bajo se confrontarán a menudo para destacar la identidad totémica que asumen los personajes de esa institución. En efecto, el último será necesario para corroborar que el ámbito donde se despliegan es concomitante de ese centro educativo, en el que la violencia es un elemento ineludible para desenvolverse y sobrevivir.

\section{Los niveles de lenguaje $\mathrm{e}^{4}$}

Según Lotman (1998, p. 78), estos se detectan cuando se articulan grupos y estructuras que se internalizan en el individuo. Estos factores exógenos instauran un sistema codificante secundario, que simplifica y unifica ese sistema común para todos. Se trata de una única norma lingüística en un determinado medio social que, a la vez, irá precedida por el desarrollo de variadas instancias de expresión lingüística. No obstante, también, se manifiesta por la exposición de sus actos, ya sean buenos o malos, según el grupo dominante del cual proviene el sujeto. El lenguaje de los cadetes del Leoncio Prado se homogeniza: todos procuran ser violentos, se expresarán y actuarán en función de la formación explícita e implícita que se demuestra en el universo castrense (caracterizado por el uso deliberado de lisuras y agresiones). Por ese motivo, a continuación, se insertarán representaciones verbales de personajes que pertenecen a esa escuela, quienes cuentan con una constante particular: la violencia. Sobre la base de esta configuración, se aludirán a los personajes del Jaguar, el Poeta, el Esclavo, el Boa, el serrano Cava, el brigadier Arróspide, los tenientes Gamboa, Huarina y Pitaluga, así como el enfermero del colegio.

\footnotetext{
4 Los niveles de lenguaje en La ciudad y los perros han sido apreciados por la crítica literaria como estrategias que sirven al autor para exponer la diversidad de dialectos existentes en el Perú. Todo ello tiene por finalidad generar una sensación de heterogeneidad social, realismo y originalidad. El exégeta Martín (1979, p. 224) se percata de ello, y pone como ejemplos las aglutinaciones y el expresionismo fortuito. Gnutzmann (1992, p. 182) agrega los limeñismos y los americanismos. Y, para terminar, Castro-Klarén (2006, p. 33) destaca todo aquello que se relaciona con la oralidad. Estos elementos serían funcionales para construir esa atmósfera de verosimilitud que logra con destreza el novelista peruano Vargas Llosa.
} 
El lenguaje empleado por el Jaguar se plasma mediante los siguientes diálogos: “Eres imbécil? [...]. Te dije que no tenemos el examen. No vuelvas a hablar de eso. Por tu bien" (Vargas Llosa, 2012, p. 50), "Un hijo de puta ha ido a decirle cosas a Gamboa" (Vargas Llosa, 2012, p. 396) y “¡Mierda! [...]. ¡Indio bruto! ¡Animal! [...]. Lo has hecho a propósito [...]. Maricón" (Vargas Llosa, 2012, p. 412). Igualmente, el Poeta se rige de la misma manera: “¿Estás cojudo? Voy a ser ingeniero [...]. ¿De qué mierda estás llorando?” (Vargas Llosa, 2012, pp. 27-28), "Si lo tocas, te rompo la cara" (Vargas Llosa, 2012, p. 143) y "Llame al médico, carajo [...]. Maldita sea, llame al médico" (Vargas Llosa, 2012, p. 233). Por otro lado, el Esclavo no manifestará acciones ni lenguaje ofensivos en su mayoría, pero sí los recibe y los conoce. En cambio, con el Boa, sí es propicio este desenvolvimiento: "Baja, baja maricón" (Vargas Llosa, 2012, p. 423) o "No le creas, Jaguar. Nadie piensa que tú eres un soplón, ni uno solo se atrevería. Dile que es mentira y rómpele la cara" (Vargas Llosa, 2012, p. 423). Esto ocurre también con el serrano Cava: "No duerme nunca la maldita" (Vargas Llosa, 2012, p. 12), el brigadier Arróspide: "Eres un soplón, Jaguar [...]. Te lo vuelvo a decir. Un soplón de porquería" (Vargas Llosa, 2012, p. 423), el teniente Gamboa: “iSilencio, carajo!” (Vargas Llosa, 2012, p. 48), el teniente Huarina: " $¡ Y$ Yo no soy un cura, qué carajo! ¡Váyase a hacer consultas morales a su padre o a su madre! [...]. Es usted un tarado, qué carajo" (Vargas Llosa, 2012, pp. 20-21), el teniente Pitaluga: "No friegues, hombre" (Vargas Llosa, 2012, p. 203) y el enfermero de ese centro educativo: "En este colegio todos son unos salvajes" (Vargas Llosa, 2012, p. 233).

Como epítome, el modo de expresarse de los personajes a través de un dialecto agresivo y ofensivo será una constante en el texto, merced a que todos ellos han sido sometidos a un adiestramiento similar, en el que la violencia es indispensable para forjar su identidad totémica, la cual está en colisión consuetudinaria con los integrantes de esa institución militar.

\section{La diégesis en la novela de Mario Vargas Llosa desde sus técnicas literarias}

Según Genette (1989, p. 85), la diégesis es el relato puro, instituido por un discurso oral o escrito, que se encarga de contar el narrador. Su abordaje dependerá de los recursos técnicos y estilísticos. En esta oportunidad, la diégesis se desarrolla de dos formas, que se correlacionan con el dominio de la información y el tiempo. Estos componentes serán ineludibles para detectar cómo el autor agrega datos relevantes que evidencian el interés por plasmar la violencia en sus personajes y atribuirles hegemonía.

\section{La diégesis, supeditada al dominio de la información}

El autor es el responsable por antonomasia de saber dominar la diégesis en los momentos adecuados, a causa de que tiene la función de no entorpecer la tensión que se produce en la obra e inducir a una expectativa en el lector. Muchas veces, frecuenta técnicas literarias para revelar la información paulatinamente, ya sea por el mismo tratamiento de la historia o empleando remitentes; aunque, además, puede brindarla en una situación inesperada. La diégesis no siempre se constituye o se orienta a la representación del bien o el éxito de las acciones éticas positivas; ya que, de ser así, la lógica argumental se transgrede. Esta será justificable en el medio real textual en el que se ha planteado, así se recurra al mal como talante triunfador. Existen muchas formas de ir esclareciendo o estructurando la diégesis de la novela. Estas se configuran a través de la trama, la paralipsis, la paralepsis, los vasos comunicantes, las cajas chinas, la confesión, la sorpresa y el suspenso. Con estos recursos, se exhibirá cómo los personajes adoptan un rol de victimario o víctima de la violencia, con el propósito de observar la hegemonía que irán consolidando.

Primero, la trama es la organización de acciones, argumentos o hechos supeditados a una continuidad coherente (Hawthorn, 1997, p. 125). Esta puede estar ordenada, como también no, al igual que iniciar desde la mitad de la historia: in medias res. La distribución de La ciudad y los perros (Vargas Llosa, 2012) presenta una sucesión lógica, puesto que se muestra en concordancia todo el ciclo de la criminalidad: el robo del examen de Química (pp. 13-14), la acusación del Esclavo al teniente Huarina sobre la infracción (p. 157), el disparo deliberado del Jaguar a Ricardo Arana (p. 224), su muerte (p. 277), la delación de Alberto Fernández al teniente Gamboa acerca del homicidio (p. 329), el castigo provisional al Jaguar (pp. 363-368) y la sanción o el chantaje impuesto al Poeta por la institución castrense (p. 390), a pesar de que se exponen historias entrecruzadas y desordenadas, en las que predomina el cambio de personajes, tiempos y espacios, sin que contribuyan muchas veces al desenlace primordial, como los consuetudinarios monólogos del 
Boa, tal como se aprecia a continuación: "No creo que exista el diablo pero el Jaguar me hace dudar a veces. Él dice que no cree, pero es mentira, pura pose. Se vio cuando le pegó a Arróspide por hablar mal de Santa Rosa" (p. 186).

Segundo, la paralipsis es definida por Genette (1998, pp. 46-47) como la retención o la omisión de un contenido esencial. Asimismo, es un dato escondido o un referente obviado al lector. Un ejemplo peculiar en la obra es el generado por la supuesta duplicidad de los personajes. Se confunden los monólogos de Alberto Fernández con los del Jaguar cuando se desenvuelven fuera de la escuela, ya que ambos tienen en común la frecuencia con Teresa. Esto se observa en el siguiente fragmento: "Tere iba a almorzar donde unos parientes, cerca de su colegio, en Lima. Yo había pensado ir al mediodía, acompañarla hasta la casa de sus parientes, así caminaríamos juntos un rato" (Vargas Llosa, 2012, p. 131). Eso ocurre al no exhibirse los nombres específicos en la mayoría de sus participaciones, porque se pretende trastocar la identificación de la autoría de los monólogos manifestados.

Tercero, la paralepsis, para Genette (1998, pp. 46-47), es la información que sobrepasa la lógica de lo inteligible; a la vez, es redundante. Se tiene como paradigma la intervención en primera persona del Boa, si bien es infalible su existencia en la novela, junto a la de los demás cadetes que subyacen a la sección, su desempeño como narrador personaje no cumple una función esencial e imprescindible para el progreso de la diégesis, tal como se aprecia en el siguiente monólogo, que cuenta sucesos distanciados de la trama: "Pero cuando rompimos filas me hice el disimulado. Ven Malpapeada, perrita, qué graciosa eres, chusquita, ven. Y vino. Todo es culpa suya, por confiada, si en ese momento se escapa, después hubiera sido otra cosa. Me compadezco de ella" (Vargas Llosa, 2012, p. 264). Sus monólogos abordan los temas de la angustia, los excesos hacia la perra Malpapeada y su intento por querer desentrañar lo que piensan los personajes, como el Jaguar, el serrano Cava o Ricardo Arana.

Cuarto, para Shaw (1999, pp. 244-245) y Gálvez (1992, pp. 96-97), los vasos comunicantes ${ }^{5}$ se estriban en la concatenación de acontecimientos o espacios heteróclitos que el lector ha logrado interpretar por la suspicacia narrativa que le exige implícitamente el au-

5 La técnica de los vasos comunicantes en La ciudad y los perros ha sido estudiada con rigurosidad por Moreno (1987, p. 87). Más allá de la definición conceptual, una de las definiciones que ella maneja es que este recurso literario es de utilidad para originar sorpresa durante la lectura. tor. Esta técnica se plasma al relatarse eventos remotos de los protagonistas (el Jaguar, el Esclavo y el Poeta), con la finalidad de conocer más de sus psicologías. En algunas circunstancias, su violencia se justifica por la mala constitución familiar y el entorno en el que se desenvuelven. Estos dos casos se observan en Ricardo Arana. El primero se muestra cuando es sometido a agresión física por parte de su progenitor: "Su padre lo golpeó con la mano abierta y él se desplomó sin gritar. [...]. Iba a decir que a él no le habían pegado nunca, que no era posible, pero antes que lo hiciera, su padre lo volvió a golpear" (Vargas Llosa, 2012, p. 96). Y el segundo caso se constata al corroborar el desprecio que padece de sus compañeros: "En el colegio salesiano le decían 'muñeca'; era tímido y todo lo asustaba. 'Llora, llora, muñeca', gritaban” (p. 155).

Quinto, para Niñapayta citado en Tenorio (2001, p. 59), las cajas chinas remiten a la incorporación de historias inusitadas que son expresadas por los protagonistas. Estas subyacen a una narración más global que las respalda. Shaw (1999, pp. 244-245) las considera como "el relato dentro del relato". Su comprensión y su eficacia serán propicias por los conocimientos literarios del lector. De ser pertinente esa modalidad de enunciación, se provocarán reiteradas transformaciones con respecto a la percepción de la diégesis. Un ejemplo notorio se evidencia casi al final de la novela, cuando el flaco Higueras y el Jaguar dialogan en un tiempo determinado sobre sucesos pasados: "Le dije otra vez: 'Hola, Teresa. ¿No te acuerdas de mí?"” (Vargas Llosa, 2012, p. 460). En estos, se involucra el Jaguar mismo y Teresa, mas no se trata de una narración analéptica (caracterizada por contar un relato en tiempo remoto sin alteraciones de tiempos), sino del recurso de las cajas chinas, ya que, a menudo, se confronta con el tiempo en el que suscita la conversación del Jaguar con el flaco Higueras (pp. 460-469), junto con el pretérito, en el que se desarrollan las vivencias pasadas del Jaguar y Teresa. Los diálogos son conducidos a ese tiempo y los personajes se autorrepresentan, con la simulación de existir en un periodo que no les corresponde. A la vez, se cumple esta técnica: la introducción frecuente de escenas y personajes. Mientras el Jaguar narra, añade a Teresa; luego, al cura y, después, a una tía p. 468).

Sexto, la confesión (Bajtín, 1998, p. 335) es la forma superior de una autorrevelación libre del hombre. Esta acción tiene el motivo de reconciliar y justificar comportamientos erróneos remotos. En La ciudad y los perros, esta develación suscita cuando el Jaguar 
le manifiesta al teniente Gamboa las causas que lo indujeron al asesinato de Ricardo Arana, tal como se expresa a continuación: "Todos lo batíamos, es la pura verdad, hasta cansarnos, yo más que los otros. [...]. Le juro que en el fondo no sé cómo lo hice. Yo había pensado pegarle, darle un susto" (Vargas Llosa, 2012, p. 445).

Séptimo, para Todorov (1971, pp. 229-230), la sorpresa ${ }^{6}$ se produce cuando acontece algo imprevisto. También, se presenta cuando ya se ha construido una atmósfera de suspenso en la diégesis. Verbigracia, luego de que el Esclavo acusa al serrano Cava (Vargas Llosa, 2012, p. 157), no se espera una venganza en su contra por haber inducido a la expulsión de uno de los mejores compañeros del Jaguar. El disparo impactado en su cabeza es una repercusión inadvertida para el lector (p. 224).

Octavo, para Roland Barthes (1977, p. 49), el suspenso $^{7}$ es la provocación de una angustia placentera y distorsionada en el lector que se ha producido por la inserción de elementos técnicos en la narración. En especial, ese estado originado conlleva una confusión coherente, bajo la égida de inferir dos o más alternativas de solución a un hecho significativo. A ese porvenir incierto, Todorov (1971, p. 194) ha demostrado su mayor interés, puesto que ignorar el tiempo y las consecuencias de la representación de lo omiso será lo más intrigante, en vez de la propia revelación. Eso es lo que mantendrá la tensión. Sobre esto, es indispensable precisar que ese dominio de información es culminante para el lector cuando conoce quién es el responsable del asesinato de Ricardo Arana (el Jaguar), pero las frecuentes contradicciones planteadas en el texto, por parte del homicida, con su cinismo y su negación de los sucesos, posibilitan la permanencia del suspenso, hasta que se evidencie la verdad en función de lo expuesto. Se espera la confidencia del criminal concomitante, tal como se expresa a continuación:

6 La técnica de la sorpresa en la novela de Vargas Llosa es importante, porque es la finalidad de la multiplicidad de recursos literarios que se encuentran en el texto. Quienes han estudiado este tema han sido los críticos León (2010) y Perera (1980, p. 821).

7 La técnica del suspenso en La ciudad y los perros ha sido trabajada desde los estudios literarios por Baker (1977), Edwards (2011, p. 24), Fontaine (2012) y Harss (1966, p. 436). Ellos, a diferencia de la definición que proponen los teóricos Barthes (1977) y Todorov (1971), brindan una explicación que se orienta a la parte expositiva y particular de la novela; es más, justifican que este recurso dependerá del buen dominio que ejerza el autor con respecto a una determinada técnica, así sean las mudas o los saltos cualitativos.
Pero esa mañana lo vi, ahí al frente, con la cabeza levantada y le apunté. Yo quería vengar a la sección [...]. Creo que lo mejor es que me metan a la cárcel. Todos decían que iba a terminar así (Vargas Llosa, 2012, p. 445).

Para conseguir este recurso estilístico mencionado, se transitan por tres momentos, estribados en la no aceptación de la culpabilidad de los hechos y su respectiva revelación. En rigor, el primero se origina en la conversación del Jaguar con el teniente Gamboa. En esa oportunidad, el lector sabe quién es el autor del homicidio. Sin embargo, resiste el cinismo del personaje, al igual que el desconocimiento y el escepticismo que posee el oficial en torno a la conducta del asesino. El segundo es similar al primero: el lector se provoca una tensión y un suspenso, a causa de que sabe que el Jaguar adopta una postura cínica para ocultar la veracidad, tal como se muestra al rechazar la acusación emitida por el teniente Gamboa: "Yo no he matado a nadie. ¿Por qué dice usted eso? ¿Cree que soy un asesino? ¿Por qué iba a matar al Esclavo?" (Vargas Llosa, 2012, p. 368). En esa ocasión, el homicida tendrá que negar su accionar frente a Alberto Fernández, el mejor amigo de Ricardo Arana (Vargas Llosa, 2012, p. 397). En ese instante, se produce tensión. Para finalizar, en el tercero, concluye el suspenso, ya que el lector manifiesta el conocimiento almacenado sobre el autor de esa muerte. En el siguiente fragmento, el Jaguar no hace más que revelar la verdad que estaba siendo puesta en expectativa.

Yo quería vengar a la sección, ¿cómo podía saber que los otros eran peores que él, mi teniente? Creo que lo mejor es que me metan a la cárcel. Todos decían que iba a terminar así, mi madre, usted también. Ya puede darse gusto, mi teniente (Vargas Llosa, 2012, p. 445).

Como epítome, estas ocho técnicas literarias basadas en la distribución consciente y múltiple de la diégesis se orientan a la representación constante de la violencia que prevalece en La ciudad y los perros. El autor maneja con éxito el desarrollo de la información que va articulándose con el propósito de que su argumentación sea verosímil en cuanto el dramatismo que se va incorporando en su historia.

\section{La diégesis, supeditada al dominio del tiempo}

Ricoeur (1995, p. 574) define el tiempo como activo, porque induce al cambio. Este se plasma con mí- 
mesis desde la cronología, la linealidad y la coherencia, como también importará cómo se estructura desde su correspondencia con el espacio, mediante técnicas literarias. Para Ricoeur (1996, p. 750), será factible que, con esa organización temporal, se detecten segmentos o acontecimientos significativos de la historia del relato. Las principales formas que se utilizan como recursos estilísticos se componen de tres instancias: el presente, el pasado (analepsis) y el futuro (prolepsis); aunque, igualmente, se evidencian otras modalidades.

Primero, el presente ${ }^{8}$ es un hecho indivisible o el punto de partida que exige movilidad. Para Genette (1989, p. 280), este coincide con el acto de la escritura. Entretanto, según Ricoeur (1996, p. 752), se trata de la circunstancia donde se forja la preocupación. Este facilita el tránsito hacia el futuro o el pasado, así como se modifican los personajes, con simultaneidad o intercalándose, debido a que eso lo permite. La mayoría de la novela de Vargas Llosa está contada en pretérito. Por lo tanto, rastros del presente se adhieren a la reproducción de los diálogos, que provocan la sensación de que se expresan paralelamente con la duración de la lectura, al igual que descripciones con respecto a impresiones de sucesos, tal como se muestra a continuación: "Era peor que si la capilla hubiera estado a oscuras. La media luz intermitente provocaba sombras, registraba cada movimiento y lo repetía en las paredes o en las losetas, divulgándolo a los ojos de todos los presentes" (Vargas Llosa, 2012, p. 294).

Segundo, la analepsis ${ }^{9}$ o el flashback evoca a sucesos originados en el pasado (Genette, 1989, pp. 9495), como cuando se aborda la historicidad (Ricoeur, 1996, p. 752), la retrospección que es narrada por el personaje. Consiste en un relato anterior al texto: secundario, caracterizado de dos formas, según Bal (1990, p. 68). Por un lado, se trata de una retrospección externa cuando se alude a eventos remotos o actores, como cuando el narrador inserta la historia de Ricardo Arana al estar en el momento de entablar comunicación por primera vez con su progenitor: "Y sintió, de

8 El tiempo presente en La ciudad y los perros es entendido por la crítica literaria como una buena oportunidad para revelar y consolidar la identidad de los personajes, la cual se complementará con las descripciones que se realicen con el uso de otros tiempos, como los que implican exponer testimonios o relatos pretéritos. Esa argumentación se halla en el libro publicado en conjunto por Vargas Llosa y colaboradores (1987).

9 La analepsis sirve para terminar de consolidar las identidades complejas de los personajes de La ciudad y los perros. Es así como lo entienden los críticos literarios Kerr (1983, p. 20) y Sommers (1976). nuevo, una ansiedad feroz, como tres días antes, cuando su madre, [...], le dijo: 'Tu papá no estaba muerto, era mentira. Acaba de volver de un viaje muy largo y nos espera en Lima"" (Vargas Llosa, 2012, p. 15). Por otro lado, se corrobora con una retrospección interna, que coincide con la diégesis primordial, considerando la idea de continuidad temporal. Un caso particular se halla cuando Alberto Fernández escucha del Esclavo cómo conoció a Teresa: "La veía pasar todos los días por mi casa. Y me la quedaba mirando desde la ventana y a veces la saludaba. [...]. Me gustaba verla. [...]. Y un día bajé poco antes de que saliera. [...]" (Vargas Llosa, 2012, p. 150).

Tercero, la prolepsis remite a una frecuencia narrativa (Genette, 1989, pp. 121-125), así como a un tránsito al futuro (una anticipación). Para Ricoeur (1996, p. 752), este tiempo es esencial porque se proyecta lo más preeminente de las acciones. Por ejemplo, cuando el Poeta acusa al asesino de Ricardo Arana, imagina qué se desembocará luego de esa colisión: "Eres un desgraciado, Jaguar. Ahora te van a expulsar. ¿Sabes cuál va a ser tu vida? La de un delincuente, te meterán a la cárcel tarde o temprano" (Vargas Llosa, 2012, p. 398).

Cuarto, existen otras formas de abordar el tiempo si es que se refieren a las definiciones de intratemporalidad, eternidad, digresión, velocidades y frecuencias narrativas.

La intratemporalidad, para Ricoeur (1996, p. 750), es el conjunto de experiencias que sirve como soporte para corroborar con los acontecimientos en un determinado tiempo. Verbigracia, si se requiere contar un evento exclusivo del libro, se señala una secuencia identificable e importante de la diégesis, como la pelea del reciente ingresante el Jaguar contra los alumnos del cuarto año del Leoncio Prado para no dejarse "bautizar" (Vargas Llosa, 2012, p. 62). La intratemporalidad no solo consiste en mencionar un hecho de los múltiples que se exponen dentro de un conjunto narrativo, sino que procura explicar otras cualidades temporales, como su objetividad (considerando la cronología, si se percibe la coincidencia del tiempo de lectura con el intrínseco que desarrolla la historia del relato) y su subjetividad (alude a lo psicológico, al notar que el tiempo de lectura es heteróclito del interno). Para Ricoeur (1996, pp. 752-754), estas particularidades se observan con las tres categorías de la intratemporalidad: la databilidad, la extensión y el carácter público. Primero, la databilidad se vincula con "contar el tiempo" (Ricoeur, 1996, pp. 752-754). En la novela, se 
aprecia esta modalidad cuando un suceso es traspuesto por la tensión. Un ejemplo inminente es cuando el Poeta y el Jaguar entran a la misma celda: "Alberto se aproximó. Ahora estaba de pie, a unos centímetros del Jaguar, sus rodillas se tocaban" (Vargas Llosa, 2012, p. 396). Allí, se produce la databilidad, porque se espera que en ese encuentro alguno de ellos contradiga su posición (o bien el Poeta afirma que no acusó al Jaguar, o el último negará haber asesinado al Esclavo) o se origine un conflicto a causa de la confrontación (el Poeta atacará al Jaguar por la hipótesis de que él mató a su compañero, y él se peleará con Alberto Fernández al percatarse del culpable de su acusación). Lo que se narra en ese instante transcurre con pausas e intriga, ya que se revelan verdades preeminentes que conllevarán obstáculos en esa historia. Segundo, la extensión se conforma del lapso, el intervalo temporal y la duración (Ricoeur, 1996, pp. 752-754), que son expuestos como unidades infalibles e iterativas en un tiempo diacrónico (Genette, 1989, pp. 185-187). Verbigracia, en el texto de Vargas Llosa, se observa esa situación al relatarse historias remotas. Estas poseen el distintivo de encontrarse limitadas por quien las cuenta: tienen un inicio y un final. En cambio, el dominio y el tratamiento transmutarán. Esto inducirá a que unas historias resulten más largas que otras, como cuando el Poeta profiere a su nueva pareja (Marcela) algo de su enamoramiento colegial con Teresa: “¿Cómo explicarle que, precisamente, lo único que lo avergonzaba en ese tiempo era no ser como Teresa, alguien de Lince o de Bajo el Puente, que su condición de miraflorino en el Leoncio Prado era más bien humillante?" (Vargas Llosa, 2012, p. 456). También, se desarrolla cuando el Jaguar alude al Flaco Higueras de lo ocurrido luego de la separación con la chica que tanto le gustaba hasta que se casan (Vargas Llosa, 2012, p. 468). Tercero, el carácter público es cuando el tiempo de la preocupación posee esa peculiaridad (Ricoeur, 1996, pp. 752-754). En su mayoría, se halla al existir personajes que realizan un testimonio del temor de algún individuo, como cuando el Jaguar le hace constatar al serrano Cava que se ha orinado de miedo (Vargas Llosa, 2012, p. 14) o cuando los militares quieren sancionar al culpable del robo del examen de Química: "Han descubierto el robo del examen de química. Habían roto un vidrio. Ayer vino el coronel. Gritó a los oficiales en el comedor. Todos están como fieras. Y los que estábamos de imaginaria el viernes..." (Vargas Llosa, 2012, p. 130). Por ello, los alumnos se ponen en tensión. Es más, se indica el momento en que el Jaguar es acusado de "so- plón" por sus compañeros de sección, debido a que la opinión pública es la que demandará una acción. Así, un sentimiento de culpabilidad se patentizará en ellos: una tensión.

La eternidad, para Ricoeur (1998, pp. 70-71), es siempre estable. Nada allí es ocasional. Todo está presente, en oposición al tiempo, que nunca se expone a cabalidad. Esta se contrasta con los objetos que sí son. Algo inherente en el libro son las ideas que se asumen del bien y el mal. La primera aptitud se erige a partir de actos que no demandan una agresión entre los personajes. Por ende, la percepción de la educación se instaura allí como un elemento que mejora la condición humana. Incluso, el teniente Gamboa revela esa realidad con disgusto: "A la mitad los mandan sus padres para que no sean unos bandoleros [...]. Y, a la otra mitad, para que no sean maricas" (Vargas Llosa, 2012, p. 210). Este postulado es irrefutable antes de confrontar con la novela en sí. Asimismo, la noción del mal es una construcción previa en el lector. Es perpetuo, porque en la obra literaria se detectan qué acciones son perjudiciales y merecedoras de castigo, sin cuestionarlas, como al tener conciencia del significado de las palabras "ángulo recto o seis puntos" (Vargas Llosa, 2012, p. 49); incluso, les causa ironía presenciar el maltrato que padecen estos cadetes al recibir una patada o permanecer en la institución, producto de la acumulación de sanciones.

La digresión ${ }^{10}$ se considera una anacronía (Genette, 1989, pp. 92-104) por la inexistencia de reciprocidad y orden estructural entre tiempo e historia de la diégesis. Se halla descronologizado y no se expone en lo intrínseco del texto ficcional (Doležel, 1999, p. 52), aunque se supedite al relato central a través de expresiones (opiniones o creencias) acerca del mundo real. Esto es culminante al corroborarse en La ciudady los perros el ocultamiento provisional de la autoría de monólogos protagónicos, como se genera con Alberto Fernández (Vargas Llosa, 2012, pp. 447-459) y el Jaguar (pp. 460-469) al reconocerlos al final del libro (ya con más edad). En ese sentido, se proyectan hacia un tiempo inminente, que abarca el término de sus etapas escolares.

10 La técnica literaria de la digresión en La ciudad y los perros procura ocultar información importante para ir revelándola poco a poco, tal como sucede con la aclaración del responsable del asesinato de Ricardo Arana. Lo que se suele eludir en esta novela son diálogos, identidades y eventualidades. En ese sentido, se trata de una retención y no de una omisión. Quienes han examinado este tema han sido Castañeda (1987, p. 135), de Felipe (2012, p. 90) y Díaz Reategui (2004, p. 62). 
Las velocidades narrativas son formuladas por Genette en Figuras III (1989). En este, el autor propone cuatro tipos: la elipsis, la pausa, la escena y el resumen. Primero, la elipsis es la ausencia del relato (Genette, 1989, p. 161), así como la omisión de un periodo de tiempo, que obvia eventos de la diégesis que se recuperan en la retrospección. Además, adopta la forma de pausas descriptivas. Un acontecimiento que no se relata en la obra es si el Esclavo practicó alguna vez la violencia física o verbal contra cadetes de esa escuela que cursaban rangos inferiores al suyo, por más que se conoce que el personaje no se desenvuelve con agresividad, tal como se lo advierte el Poeta: "Hay que trompearse de vez en cuando para hacerse respetar. [...]. Aquí eres militar aunque no quieras. Y lo que importa en el Ejército es ser bien macho, tener unos huevos de acero, ¿comprendes? O comes o te comen" (Vargas Llosa, 2012, p. 26). Segundo, la pausa es la pormenorización de objetos, personajes o lugares que, para Genette (1989, pp. 155-164), se logra mediante descripciones iterativas desligadas de la historia y el dramatismo. Estas no contribuyen a su condensación; más bien, su intención es abordar instancias paralelas y autónomas con respecto al eje de la narración. Asimismo, se trata del cambio de una escena por otra, para dejar la primera inconclusa. La finalidad es retardar el avance de la historia. Un ejemplo concreto es en la participación postrema del Poeta, cuando él ya no cuenta con ni una función más para desarrollar en la novela, y su aparición se dedica tan solo a una mera descripción sin intensidad: "A cada momento, tenía que limpiarse el rostro con la toalla. La avenida estaba desierta y era extraño: por lo general, a esa hora comenzaba el desfile de automóviles hacia las playas" (Vargas Llosa, 2012, p. 447). Tercero, la escena se conforma por los diálogos de los personajes, distinguidos por su estilo directo. Se reconoce quién es el propietario de la voz enunciada; en rigor, se exponen talantes consuetudinarios que erigen esa demarcación y se articula un dramatismo determinado (Genette, 1989, p. 164). Ejemplos eximios son notorios en las conversaciones cotidianas de esos cadetes, como cuando el negro Vallano habla con Alberto Fernández: "Poeta — gritó Vallano-. ¿Tú has estado en el colegio La Salle?" (Vargas Llosa, 2012, p. 161). Cuarto, el resumen es lo sucedido en el tiempo. Genette $(1989$, p. 152) lo denomina sumario. Este consiste en la abreviación o la síntesis de escenas y elisiones. En el libro, se alude a esta modalidad cuando se cuentan escenas que no se requieren traer al presente con detalles, diálogos o personajes. Simplemente, se narran para tratar de completar una característica en los protagonistas. En el caso que se cita a continuación, se muestra una configuración más amplia de Ricardo Arana (saber si él ha empleado la violencia alguna vez, aunque el texto no precise cómo), al ser interrogado por el Poeta: “¿Tú no has peleado nunca, no? - Solo una vez — dice el Esclavo. — ¿Aquí? —No. Antes" (Vargas Llosa, 2012, p. 26).

La frecuencia narrativa es definida por Genette (1989, p. 172) como el aspecto estribado en la repetición entre relato y diégesis; es decir, lo rutinario y lo monótono se insertan en el plano de lo esperado, ya sea de forma ordenada o desordenada, aunque con el propósito de configurar una acción del mejor modo. Se coteja con las iteraciones de la historia (Genette, 1989, p. 91). Considerando lo formulado por Todorov (1971, p. 216), se trata de corroborar con lo natural; de ello, lo complejo o lo figurado se distancian de esa construcción para retomar lo habitual y lo ordinario que son aludidos por Fontaine (2012). Esta técnica literaria se observa con eficacia en La ciudad y los perros. Un momento destacable es cuando Alberto Fernández es referido con el sobrenombre de Poeta: determinación que se ha conseguido por su actuar peculiar, tal como se representan en ejemplos comunes y reiterantes. En una primera ocasión, se expone lo siguiente: “-iTú vas a ser un poeta? - dice el Esclavo. — ¿Estás cojudo? Voy a ser ingeniero [...]. Escribo cartas y novelitas para comprarme cigarrillos. Pero eso no quiere decir nada" (Vargas Llosa, 2012, p. 27). Posteriormente, se manifiesta de la siguiente manera: "- ¿Puedes prestarme veinte soles? —Veinte soles, sí. Alberto le da una palmada en el hombro. Dice: -Formidable, formidable. Estaba sin un centavo. Si quieres, te puedo pagar con novelitas" (p. 31). Asimismo: “¿No tienen una novelita? ¿Y si traemos al Poeta a que le cuente una de esas historias que engordan la pichula?" (p. 38). Como cuarto ejemplo, se muestra cómo el personaje consolida sus relatos: “"Tenía las piernas gordas, blancas y sin pelos [...]'. Alberto se quedó mirando la frase, tratando de calcular sus posibilidades eróticas, y la encontró bien" (p. 163). Para finiquitar, esa condensación ya es conocida por sus compañeros: "'Poeta, hazme una poesía a esto' [...]. 'Ahorita te la hago', dijo el Poeta, 'déjame que me inspire'. Y al poco rato nos la recitaba: 'El pipí, donde Vallano, tiene la mano, parece un maní'” (p. 306). Con estos ejemplos, se comprueba que la frecuencia delimita y orienta los tópicos que se abordarán en lo sucesivo, ya 
que se tiene como un indicador el lugar de procedencia de los actos concomitantes de los estudiantes de ese centro educativo.

Recapitulando, estas propuestas temporales que domina el autor permitieron constatar la multiplicidad de maneras que existen para plasmar la violencia en situaciones y personajes, con la finalidad de reincidir en los caracteres que prevalecen en un universo donde la trifulca y la imposición son determinantes para un óptimo funcionamiento en el ámbito militar.

\section{A manera de conclusión}

De esta pesquisa, se logró identificar los diversos modos de expresar la violencia en la obra literaria de Mario Vargas Llosa. Encima, el referente donde oscilaron los actos narrativos afines se adecuó a las vivencias subyacentes a la instrucción castrense, en la que los tratos belicosos son parte de su cotidianidad. Asimismo, se destacó la noción de que se pretende construir un prototipo basado en la adquisición de poder, el cual sería indispensable para asimilar la formación del Colegio Militar Leoncio Prado y subsistir en ese medio caótico. Además, el autor se valió de todas las variantes asequibles para erigir una atmósfera supeditada a la agresividad constante, la cual era reconocida de inmediato por el lector. Un ejemplo de ello es cuando este se formula un criterio de la sanción idónea que se merecería el asesino del Esclavo.

Con respecto al estilo, se tomaron como precedentes los estudios realizados por Rama (2005/1984), Urroz (2011) y Valencia (1976) y se desarrolló la teoría de Todorov (1971) que explica la importancia de la representación y la perspectiva que se incluye en la diégesis. Se consideró la taxonomía de los estilos: el directo, el indirecto y el indirecto libre, según Hamburger (1975), Todorov (1971) y Vargas Llosa y colaboradores (1987) para localizar el desempeño peculiar del Jaguar en La ciudad y los perros, orientado a apropiarse de una hegemonía diferenciada y preeminente. Luego, se trabajaron los estilos literarios (propuesta de Todorov, 1971) y los niveles de lenguaje (nomenclatura de Lotman y objeto de análisis para los exégetas Castro-Klarén, 2006; Gnutzmann, 1992; Martín, 1979), que coincidieron en el uso obligatorio del habla agresiva, característica del exigente y preponderante entorno castrense.

Acerca de las técnicas empleadas, se retomaron las aseveraciones de Genette $(1989,1998)$ para manifestar que lo diverso era propicio para originar una atmósfera prevaleciente sobre las conductas violentas y totémicas que se reforzaban, como al percatarse de la negación del Jaguar al sometimiento del abuso tradicional de la escuela. Desde lo informativo, se asumió la noción del autor para organizar su novela y conseguir la perlocución en el lector, como al existir dudas para reconocer con certeza de que el Jaguar mató a Ricardo Arana o cerciorarse del problema generado por la confusa identificación de los protagonistas desde sus monólogos. Para ello, se explicaron los recursos de la trama, la paralipsis, la paralepsis, los vasos comunicantes, las cajas chinas, la confesión, la sorpresa y el suspenso, que fueron elaborados por Bajtín (1998), Barthes (1977), Gálvez (1992), Genette (1989, 1998), Hawthorn (1997), Niñapayta citado por Tenorio (2001), Shaw (1999) y Todorov (1971), además de ser estudiados por los críticos Baker (1977), Edwards (2011), Fontaine (2012), Harss (1966), León (2010), Moreno (1987) y Perera (1980). Y desde lo temporal, tomando en cuenta las investigaciones de Castañeda (1987), de Felipe (2012), Díaz Reategui (2004), Kerr (1983) y Sommers (1976), se reanudó el planteamiento de Ricoeur para comprender el dinamismo de las variantes del presente, el pasado y el futuro, como la intratemporalidad, la eternidad, la digresión, las velocidades y las frecuencias narrativas, que son trabajadas por Doležel (1999), Genette (1989, 1998), Ricoeur $(1995,1996,1998)$ y Todorov (1971). De estas, se extrajo su funcionalidad: reincidir en la complexión intrínseca de los personajes que procuran imponerse con agresividad y la exposición de una realidad perjudicial en el texto.

Para finiquitar, con este artículo, se comprobó que el estilo y las técnicas literarias estuvieron orientadas a plasmar un universo violento y heterogéneo en cuanto representaciones objetiva y subjetiva. Los personajes que se desenvolvieron dentro de esa institución fueron los referentes por antonomasia para corroborar la intención imperante de querer adoptar el máximo poder, con el propósito de asimilar esas vivencias inusitadas y sobrevivir en ese medio caótico.

\section{Agradecimientos}

Se agradece al Vicerrectorado de Investigación de la Universidad Nacional Mayor de San Marcos (Perú) por el financiamiento para la realización del proyecto de grado Protagonismo violento y modos de representación en La ciudad y los perros (1963), registrado con el código n. ${ }^{\circ} 120300037 \mathrm{y}$ dirigido por el asesor Marco Gerardo Martos Carrera. 


\section{Referencias}

Bajtín, M. (1998). Estética de la creación verbal. Siglo Veintiuno Editores.

Baker, R. (1977). "Of How to be and what to see While you are Being": The Reader's Performance in The Time of the Hero. Texas Studies in Literature and Language, 19(4), 396-407.

Bal, M. (1990). Teoría de la narrativa (una introducción a la narratología). Cátedra.

Barthes, R. (1977). Introducción al análisis estructural de los relatos. En S. Niccolini (Comp.), El análisis estructural (pp. 65-119). Centro Editor de América Latina.

Castañeda, B. (1987). Mario Vargas Llosa: Crítico, novelista y dramaturgo [Tesis de doctorado no publicada]. Universidad de Wisconsin.

Castro-Klarén, S. (2006). Desire, The City and the Dogs of Paradise. En M. Á. Zapata (Ed.), Mario Vargas Llosa and the Persistence of Memory: $\mathrm{Ce}$ lebrating the 40th Anniversary of La ciudad y los perros (The Time of the Hero) and Other Works (pp. 27-39). Universidad Nacional Mayor de San Marcos, Fondo Editorial, Hofstra University.

De Felipe, P. (2012). Un cuarto de siglo en la búsqueda de la felicidad en tres novelas de Mario Vargas Llosa. La ciudad y los perros (1963), La tía Julia y el escribidor (1977) y Las travesuras de la niña mala (2006). Contexto, 16(18), 85-101.

Delgado Del Aguila, J. M. (2017). Protagonismo violento y modos de representación en La ciudad y los perros (1963) [Tesis de licenciatura, Universidad Nacional Mayor de San Marcos). https://cybertesis.unmsm.edu.pe/bitstream/ handle/20.500.12672/6868/Delgado_dj.pdf?sequence $=2$

Díaz Reategui, K. (2004). Cuestiones de identidad, ficción y verosimilitud en la autobiografía latinoamericana: Antes que anochezca y La ciudad y los perros [Tesis de maestría, University of Georgia]. https://getd.libs.uga.edu/pdfs/diaz-reategui karen_200408_ma.pdf

Doležel, L. (1999). Heterocósmica. Ficción y mundos posibles. Arco Libros.

Edwards, J. (2011). Comienzos franceses. Estudios Públicos, (122), 15-24.
Fontaine, A. (2012). ¿Dónde está Vargas Llosa? A propósito de La ciudad y los perros. En Conferencia impartida en la Universidad de la Rioja (pp. 1-14). Biblioteca Virtual Miguel de Cervantes.

Gálvez, M. (1992). La novela hispanoamericana contemporánea. Taurus.

Genette, G. (1989). Figuras III. Lumen.

Genette, G. (1998). Nuevo discurso del relato. Cátedra.

Gnutzmann, R. (1992). Cómo leer a Mario Vargas Llosa. Júcar.

Hamburger, K. (1995). La lógica de la literatura. Visor.

Harss, L. (1966). Los nuestros. Editorial Sudamericana.

Hawthorn, J. (1997). Studying the Novel: An Introduction (3. $\left.{ }^{\text {a }} \mathrm{ed}\right)$. Arnold.

Kerr, R. A. (1983). The Janus Mask: Hidden Identities and the Reader's Role in Mario Vargas Llosa's Early Fiction. Chasqui: Revista de Literatura Latinoamericana, 13(1), 18-31.

León, R. (2010). Lima, los lugares de Mario Vargas Llosa. Localización: Viajar: la Primera Revista Española de Viajes, (379), 86-99.

Lotman, I. (1998). La semiósfera. Libro II: Semiótica de la cultura, del texto, de la conducta y del espacio. Cátedra.

Martín, J. L. (1979). La narrativa de Vargas Llosa; acercamiento estilístico. Gredos.

Moreno, M. (1987). La corrupción: Tema central de la novela La ciudad y los perros [Tesis de licenciatura, Universidad de San Carlos de Guatemala]. http://biblioteca.usac.edu.gt/tesis/07/07_0729.pdf

Perera, N. (1980). La ciudad y los perros, génesis de un ciclo novelesco: Análisis estilístico. En Actas del VII Congreso de la Asociación Internacional de Hispanistas (pp. 817-824). Venecia, Roma.

Rama, Á. (2005) [1984]. El boom en perspectiva. Signos Literarios, 1, 161-208.

Ricoeur, P. (1995). Tiempo y narración. Configuración del tiempo en el relato de ficción (Tomo II). Siglo Veintiuno Editores.

Ricoeur, P. (1996). Tiempo y narración. El tiempo narrado (Tomo III). Siglo Veintiuno Editores. 
Ricoeur, P. (1998). Tiempo y narración. Configuración del tiempo en el relato histórico. (Tomo I). Siglo Veintiuno Editores.

Shaw, D. (1999). Nueva narrativa hispanoamericana. Boom. Posboom. Posmodernismo (6. ${ }^{\mathrm{a}}$ ed.). Cátedra.

Sommers, J. (1976). Literatura e ideología: La evaluación novelística del militarismo en Vargas Llosa. Cuadernos Politicos, 9, 83-102.

Tenorio, N. (2001). Mario Vargas Llosa: El fuego de la literatura. Arteidea Editores.

Todorov, T. (1971). Literatura y significación. Editorial Planeta.

Urroz, E. (2011). El sueño del celta o el arte de la denuncia. Estudios Públicos, 122, 489-512.

Valencia, H. (1976). La ciudad y los perros. En Crónica de libros (pp. 133-140). Instituto Colombiano de Cultura.

Vargas Llosa, M. (1971). García Márquez: Historia de un deicidio. Barral Editores.

Vargas Llosa, M. (2012). La ciudad y los perros. Alfaguara, Real Academia Española.

Vargas Llosa, M., Lombardi, F., Bueno, G., \& Serra, P. (1987). La ciudad y los perros: The City and the Dogs. Cóndor Video. 